\title{
A Fluorescence Ratiometric Probe for Cysteine/Homocysteine and Its Application for Living Cell Imaging
}

\author{
Lingliang Long *, Lin Wang, Yanjun Wu \\ Functional Molecular Materials Research Centre, Scientific Research Academy \& School of Chemistry and \\ Chemical Engineering, Jiangsu University, Zhenjiang, China \\ Email: *linglianglong@gmail.com
}

Received November 1, 2013; revised November 29, 2013; accepted December 5, 2013

Copyright (C) 2013 Lingliang Long et al. This is an open access article distributed under the Creative Commons Attribution License, which permits unrestricted use, distribution, and reproduction in any medium, provided the original work is properly cited.

\begin{abstract}
A fluorescence ratiometric probe 1 for cysteine (Cys) and homocysteine (Hcy) has been rationally constructed based on intramolecular charge transfer (ICT) mechanism. Upon treatment with Cys/Hcy, probe 1 exhibited a fluorescence ratiometric response, with the emission wavelength displaying a large shift (from $526 \mathrm{~nm}$ to $446 \mathrm{~nm}$ ). When $90 \mu \mathrm{M} \mathrm{Cys}$ were added, the emission ratios $\left(\mathrm{I}_{446} / \mathrm{I}_{526}\right)$ of the probe changed dramatically from 0.01797 to 4.65472 . The detection limit was also measured to be $0.18 \mu \mathrm{M}(S / N=3)$. The theoretical calculations have confirmed that the ratiometric response of probe 1 to $\mathrm{Cys} / \mathrm{Hcy}$ is due to the inhibition of ICT process upon the reaction of probe $\mathbf{1}$ with Cys/Hcy. Furthermore, the fluorescence imaging experiments in living cell demonstrated that probe $\mathbf{1}$ was favourable for intracellular Cys/Hcy imaging.
\end{abstract}

Keywords: Fluorescent Probes; Fluorescence; Cysteine and Homocysteine; Fluorescence Imaging

\section{Introduction}

The thiol containing amino acids, such as cysteine (Cys) and homocysteine (Hcy), play crucial roles in numerous biological processes in living organism [1]. For example, deficiency of Cys is associated with many human diseases, such as slow growth, hair depigmentation, edema, lethargy, liver damage, loss of muscle and fat, skin lesions, and weakness [2]. Hcy is a risk factor for disorders including cardiovascular diseases and Alzheimer's disease [3]. Monitoring the concentration of biological Cys/ Hcy in living system may help in early diagnosis and prevention of such diseases. Thus, it is of great importance, both in academic research and in clinical applications, to develop efficient methods for determination of Cys/Hcy.

Among various methods for detection of Cys/Hcy, the fluorescence method based on fluorescence probe is advantageous due to its desirable features such as high sensitivity, simplicity, and potential for in vivo imaging [4]. Accordingly, in the past decade, significant efforts have been devoted to construction of fluorescent probes for

${ }^{*}$ Corresponding author.
Cys/Hcy [5]. Nevertheless, most of these probes respond to Cys/Hcy with changes only in fluorescence intensity. In a complex environment, the fluorescence signals of the intensity based probes are frequently influenced by some factors including environmental conditions, probe distribution, and instrumental efficiency [6]. By contrast, these factors can be potentially avoided by employing fluorescence ratiometric probes, as they allow the measurement of fluorescence intensities at two wavelengths [7]. However, up to now, only a few fluorescence ratiometric probes for specific detection of Cys/Hcy have been constructed [8-16].

Bearing these considerations in mind, we herein reported a fluorescence ratiometric probe, compound $\mathbf{1}$, for Cys/Hcy. Probe 1 is composed of a 4,5-di((E)-styryl) - $1 H$-imidazole dye and an aldehyde group (Scheme 1). The selection of 4,5-di((E)-styryl)-1H-imidazole is based on the consideration that it can function both as fluorescence dye and electron donor in an intramolecular charge transfer (ICT) system. The aldehyde group is a specific recognition group for Cys/Hcy. It can react with Cys and Hcy to form thiazolidine and thiazinane, respectively $[17,18]$. Moreover, the aldehyde is an electron with draw- 
a)

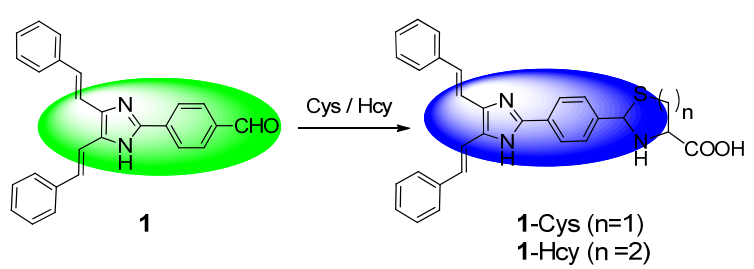

b)

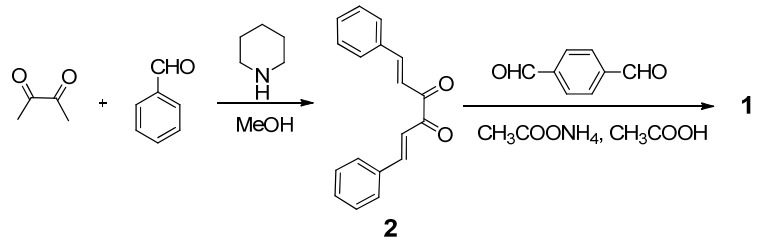

Scheme 1. (a) The sensing reaction of probe 1 with $\mathrm{Cys} / \mathrm{Hcy}$ to form 1-Cys $(n=1$, containing thiazolidine moiety)/1-Hcy ( $\mathrm{n}=2$, containing thiazinane moiety); (b) The synthetic procedures for probe 1 .

ing group, which could be used as the electron acceptor in the ICT system. Thus, upon excitation, the ICT process in probe 1 will proceed from the 4,5-di((E)-styryl)$1 \mathrm{H}$-imidazole dye to the aldehyde group. However, after reaction with Cys or Hcy, the aldehyde group in probe $\mathbf{1}$ is transformed to be the thiazolidine or thiazinane group. Thereby the ICT process will be inhibited, which results in a blue shift emission. Consequently, upon treatment with Cys/Hcy, probe 1 will show a substantial ratiometric response.

\section{Experimental Section}

\subsection{Reagents and Apparatus}

Unless otherwise stated, all reagents were purchased from commercial suppliers and used without further purification. Solvents were purified by standard methods prior to use. Twice-distilled water was used throughout all experiments.

Mass spectra were recorded on a LXQ Spectrometer (Thermo Scientific) operating on ESI. ${ }^{1} \mathrm{H}$ NMR spectra were recorded on a Bruker Avance 400 spectrometer operating at $400 \mathrm{MHz}$. Elemental $(\mathrm{C}, \mathrm{H}, \mathrm{N})$ analysis were carried out using Flash EA 1112 analyzer. Electronic absorption spectra were obtained on a SHIMADZU UV2450 spectrometer. Fluorescence spectra were measured on a Photon Technology International (PTI) Quantamaster fluorometer with $3 \mathrm{~nm}$ excitation and emission slit widths. Cells imaging were performed with an inverted fluorescence microscope (Carl Zeiss, Axio Observer A1). All $\mathrm{pH}$ measurements were performed with a $\mathrm{pH}-3 \mathrm{c}$ digital pH-meter (Shanghai ShengCi Device Works, Shanghai, China) with a combined glass-calomel electrode.

\subsection{Synthesis of Compound 2}

The synthetic procedures were showed in Scheme 1.
Under the $\mathrm{N}_{2}$ atmosphere, a solution of 2,3-butanedione $(0.4 \mathrm{ml}, 4.5 \mathrm{mmol})$, benzaldehyde $(0.92 \mathrm{ml}, 9 \mathrm{mmol})$ and piperidine (2 drops) in methanol $(10 \mathrm{ml})$ was heated under reflux for $24 \mathrm{~h}$. The solution color became brown. After cooling to room temperature, the mixture was kept in refrigerator overnight. And then, the orange precipitate was collected by filtration to afford the compound 2 (247.8 mg, yield $21 \%$ ). mp: $159^{\circ} \mathrm{C}-161^{\circ} \mathrm{C} ;{ }^{1} \mathrm{H}$ NMR $\left(\mathrm{CDCl}_{3}, 400 \mathrm{MHz}\right) \delta(\mathrm{ppm}): 7.87(\mathrm{~d}, J=16.4 \mathrm{~Hz}, 2 \mathrm{H})$, 7.67 (m, 4H), 7.49 (d, $J=16.4 \mathrm{~Hz}, 2 \mathrm{H}), 7.44$ (m, 6H); MS $(m / z): 263.2[\mathrm{M}+1]^{+}$; Anal. calcd for $\mathrm{C}_{18} \mathrm{H}_{14} \mathrm{O}_{2}: \mathrm{C}$ 82.42, H 5.38, N 0; found C 82.26, H 5.40, N 0 .

\subsection{Synthesis of Probe 1}

A solution of compound 2 (350 $\mathrm{mg}, 1.33 \mathrm{mmol}), 1,4-$ phthalaldehyde $(536 \mathrm{mg}, 4 \mathrm{mmol})$ and ammonium acetate $(2 \mathrm{~g}, 25.9 \mathrm{mmol})$ in acetic acid $(10 \mathrm{~mL})$ was heated at $100^{\circ} \mathrm{C}$ for $50 \mathrm{~min}$. The hot solution was cooled to room temperature, and the resulting precipitate was collected by filtration and washed with acetate acid, dilute sodium hydrogen carbonate solution, and water. After dried under reduced vacuum, the precipitate was further purified by column chromatography on silica gel (eluent: ethyl acetate:petroleum ether $=1: 10, \mathrm{v} / \mathrm{v}$ ) to afford the probe $\mathbf{1}$ as orange solid $(290 \mathrm{mg}, 58 \%)$ mp: $249^{\circ} \mathrm{C}-251^{\circ} \mathrm{C} ;{ }^{1} \mathrm{H}$ NMR (DMSO- $\left.d_{6}, 400 \mathrm{MHz}\right) \delta(\mathrm{ppm}): 12.75(\mathrm{~s}, 1 \mathrm{H})$, $10.06(\mathrm{~s}, 1 \mathrm{H}), 8.37(\mathrm{~d}, J=8.0 \mathrm{~Hz}, 2 \mathrm{H}), 8.06(\mathrm{~d}, J=8.0$ $\mathrm{Hz}, 2 \mathrm{H}), 7.74-7.63(\mathrm{~m}, 6 \mathrm{H}), 7.40-7.28$ (m, 8H); MS $(m / z): 377.3[\mathrm{M}+1]^{+}$; Anal. calcd for $\mathrm{C}_{26} \mathrm{H}_{20} \mathrm{~N}_{2} \mathrm{O}: \mathrm{C}$ 82.95, H 5.35, N 7.44; found C 82.78, H 5.39, N 7.40.

\section{Results and Discussions}

\subsection{Optical Response to Cys/Hcy}

The fluorescence ratiometric responses of probe $\mathbf{1}$ to Cys/Hcy were exemplified by its reaction with Cys in 20 $\mathrm{mM}$ potassium phosphate buffer/DMF (v/v 1:3, $\mathrm{pH} 7.4$ ) at room temperature. As shown in Figure 1(a), when increasing concentrations of Cys were introduced, the fluorescence emission spectra of probe $\mathbf{1}$ exhibited shift from 526 to $446 \mathrm{~nm}$ with a pronounced blue shift of 80 $\mathrm{nm}$. The large blue shift signals were apparently owing to that the ICT process in probe $\mathbf{1}$ was inhibited by reaction with Cys. The blue shift of fluorescence emission spectra also elicited an obvious variation in emission color. With the addition of Cys, the fluorescence color of probe $\mathbf{1}$ changed from green to blue (Figure 1(a), inset). A welldefined isoemission point was found at $495 \mathrm{~nm}$, indicating the reaction of probe $\mathbf{1}$ with Cys is a clear process. In addition, the emission ratio $\left(\mathrm{I}_{446} / \mathrm{I}_{526}\right)$ of probe 1 response to Cys displayed a large increase from 0.01797 to 4.65472 (259-fold enhancement) after $90 \mu \mathrm{M}$ of Cys being added. The emission ratios $\left(\mathrm{I}_{446} / \mathrm{I}_{526}\right)$ also showed a 
good linearity with Cys concentration in the range of 0 $35 \mu \mathrm{M}$ (Figure 1(b)), indicating the probe can be potentially used to quantitatively detection of Cys. The detection limit for Cys was estimated to be $0.18 \mu \mathrm{M}(S / N=3)$ according to a reported method [19]. The low detection limit together with the large emission ratio enhancement demonstrates that probe $\mathbf{1}$ is highly sensitive to Cys.

Consistent with the changes in emission spectra, addition of Cys also induced the blue shift in absorption spectra (Figure 2). When $90 \mu \mathrm{M}$ of Cys was added, the maximum absorption peak of probe $\mathbf{1}$ exhibited a blue shift from 373 to $361 \mathrm{~nm}$, with the solution color varied from yellow to colorless (Figure 2, inset). The blue shift of absorption spectra confirmed that the ICT effect of the probe 1 was inhibited along with the addition of Cys.

\subsection{Selectivity Studies}

For an excellent fluorescent probe, high selectivity is a matter of necessity. The fluorescence ratiometric response of probe 1 to various amino acids (Phe, Ala, Gly, Glu, Arg, Lys, Tys, Leu, Ser and Val) and glutathione (GSH) was also investigated. As shown in Figure 3(a), compared with that of probe 1 with Cys and Hcy, no obvious changes in emission ratios $\left(\mathrm{I}_{446} / \mathrm{I}_{526}\right)$ were observed upon addition of other amino acids and GSH, denoting that the formation of thiazolidine 1-Cys and thiazinane
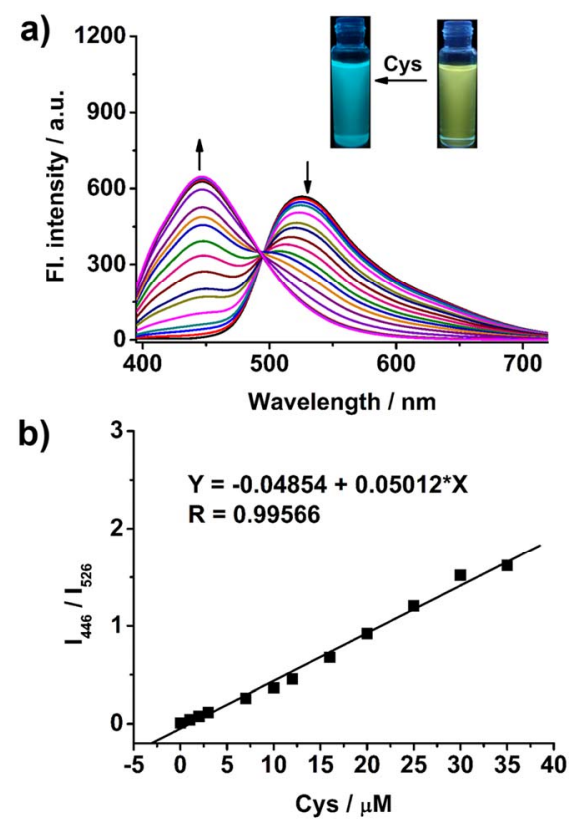

Figure 1. (a) Changes in fluorescence emission spectra $\left(\lambda_{\mathrm{ex}}=\right.$ $380 \mathrm{~nm})$ of probe $1(10 \mu \mathrm{M})$ in $20 \mathrm{mM}$ potassium phosphate buffer/DMF (v/v 1:3, pH 7.4) with various amount of Cys (0 to $90 \mu \mathrm{M})$, inset: visual fluorescence color changes of probe $1(10 \mu M)$ in the absence and presence of Cys $(90 \mu M)$, the photo was taken under illumination of a handheld UV lamp; (b) Changes in fluorescence emission ratios $\left(I_{446} / I_{526}\right)$ of probe $1(10 \mu \mathrm{M})$ to various amount of Cys (0 to $35 \mu \mathrm{M})$.

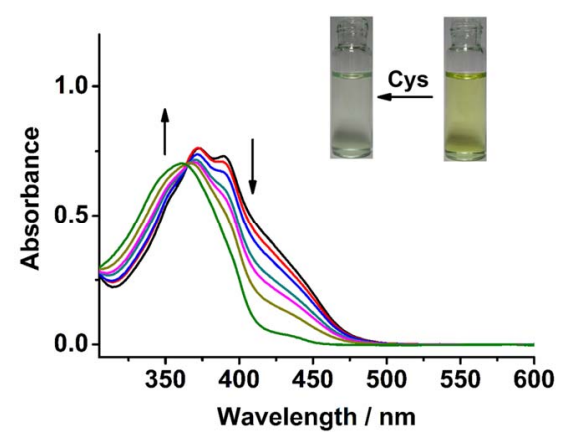

Figure 2. Changes in absorption spectra of probe $1(10 \mu \mathrm{M})$ in $20 \mathrm{mM}$ potassium phosphate buffer/DMF (v/v 1:3, pH 7.4) with various amount of Cys (0 to $90 \mu \mathrm{M})$, inset: visible color changes of probe $1(10 \mu \mathrm{M})$ in the absence and presence of Cys $(90 \mu M)$.

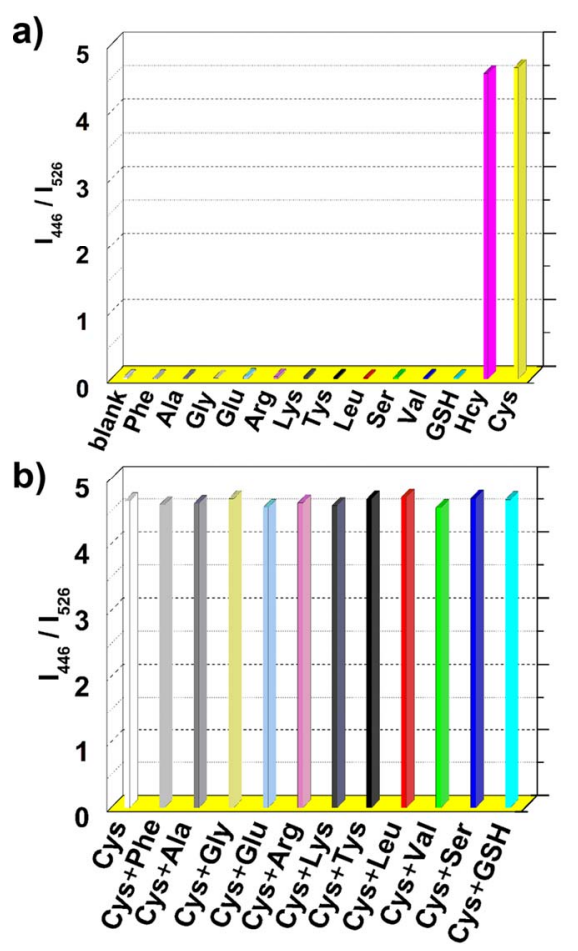

Figure 3. (a) Fluorescence ratiometric response of probe 1 $(10 \mu \mathrm{M})$ to $90 \mu \mathrm{M}$ of various amino acids in $20 \mathrm{mM}$ potassium phosphate buffer/DMF (v/v 1:3, pH 7.4); (b) fluorescence ratiometric response of probe $1(10 \mu \mathrm{M})$ to $90 \mu \mathrm{M}$ of Cys in the presence of $90 \mu \mathrm{M}$ of other amino acid.

1-Hcy was a key for the selective recognition of Cys and Hcy. Furthermore, we examined the response of probe $\mathbf{1}$ to Cys in the presence of other species, and most of the other species only displayed minimum interference (Figure 3(b)). These facts indicated a high selectivity of probe $\mathbf{1}$ in sensing Cys and Hcy.

\subsection{Theoretical Calculation.}

To better understand the optical responses of probe $\mathbf{1}$ to Cys, we carried out density functional theory (DFT) cal- 
culations at the B3LYP/6-31G* level using Gaussian 09 program. As shown in Figure 4, for probe 1, the HOMO is distributed primarily on 4,5-di((E)-styryl)- $1 H$-imidazole moiety, whereas the LUMO is delocalized over the phenyl and aldehyde moieties. Thus, it is clear that, upon excitation, the ICT will take place from 4,5-di((E)-styryl) $-1 H$-imidazole moiety to the aldehyde moiety. However, for the 1-Cys, both the HOMO and LUMO are confined to the 4,5-di((E)-styryl)-1H-imidazole moiety and the phenyl moiety. Therefore, upon excitation, the ICT process will be inhibited. Moreover, the energy gap between the HOMO and LUMO of probe $\mathbf{1}$ was smaller than that of 1-Cys, in good agreement with the blue shift of absorption and emission spectra of probe $\mathbf{1}$ upon reaction with Cys.

\subsection{Fluorescence Imaging in Living Cells}

To study the application of probe 1 for fluorescence imaging in living cells, probe $1(1 \mu \mathrm{M})$ was stained with pancreatic cancer cells for $30 \mathrm{~min}$ at $37^{\circ} \mathrm{C}$. After washed with PBS medium, the cells were used for fluorescence imaging. As shown in Figure 5, the cells exhibited strong fluorescence in the blue channel (Figure 5(b)), and nearly no fluorescence in the green channel (Figure 5(c)). These indicated that the probe was cell membrane permeable, and make fast detection of the intracellular Cys/ Hcy. On the other hand, the cells were pre-treated with $\mathrm{N}$-ethylmaleimide (NEM, as a thiol-reactive reagent [20]) to consume the intracellular Cys/Hcy, and then the cells were further incubated with probe 1. It was found that strong fluorescence was observed in the green channel (Figure 5(g)), but almost no fluorescence in the blue channel (Figure 5(f)). These results established that the probe $\mathbf{1}$ is capable of imaging Cys/Hcy in living cells.

\section{Conclusion}

A fluorescence ratiometric probe, compound 1, for Cys/
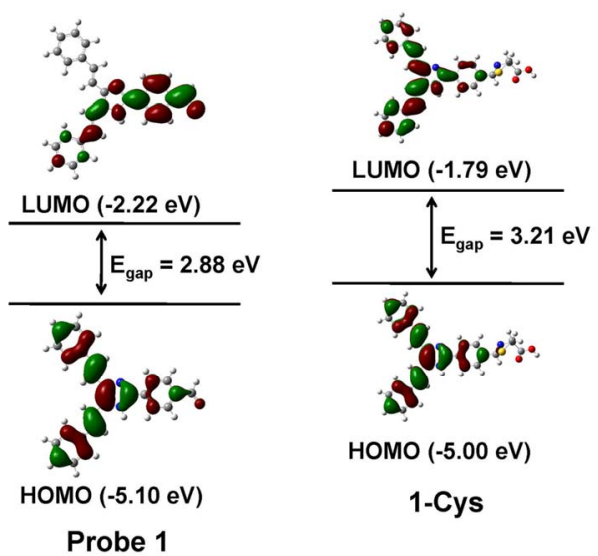

Figure 4. Calculated HOMO and LUMO distribution of probe 1 and its Cys adduct 1-Cys.

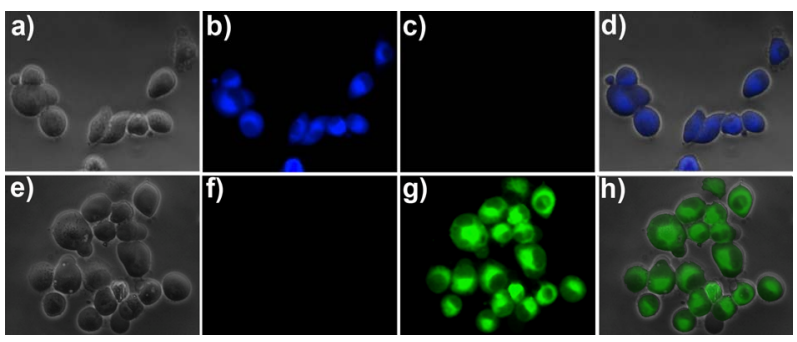

Figure 5. Fluorescence images of living pancreatic cancer cells. (a) Bright-field image of pancreatic cancer cells incubated with probe $1(1 \mu \mathrm{M})$ for $30 \mathrm{~min}$; (b) Fluorescence image of (a) with emission at $445 \pm 10 \mathrm{~nm}$; (c) Fluorescence image of (a) with emission at $530 \pm 10 \mathrm{~nm}$; (d) Overlay the images of (a), (b), and (c); (e) Bright-field image of pancreatic cancer cells pre-treated with $5 \mathrm{mM}$ NEM for $30 \mathrm{~min}$ and then incubated with probe $1(1 \mu \mathrm{M})$ for $30 \mathrm{~min}$; (f) Fluorescence image of (e) with emission at $445 \pm 10 \mathrm{~nm}$; (g) Fluorescence image of (e) with emission at $530 \pm 10 \mathrm{~nm}$; (h) Overlay the imaging of (e), (f), and (g).

Hcy has been rationally constructed with 4,5-di((E)styryl)- $1 \mathrm{H}$-imidazole as fluorophore and aldehyde as recognition group. The probe shows high sensitivity and selectivity toward Cys/Hcy. Notably, with the addition of Cys, the fluorescence emission wavelength of the probe exhibited a large shift (from 526 to $446 \mathrm{~nm}$ ), resulting in a significant change of the emission ratios (from 0.01797 to 4.65472). The theoretical calculation has confirmed that the ratiometric response of the probe to Cys/Hcy is due to the inhibition of the ICT process from 4,5di((E)-styryl)- $1 H$-imidazole to aldehyde by the reaction of probe 1 with Cys/Hcy. Importantly, the probe has been successfully applied to imaging Cys/Hcy in living cells.

\section{Acknowledgements}

This research was financially supported by National Natural Science Foundation of China (21202063), the Natural Science Foundation of Jiangsu Province (BK2012281), the China Postdoctoral Science Foundation (2012M511200), and the Research Foundation of Jiangsu University (11JDG078).

\section{REFERENCES}

[1] Z. A. Wood, E. Schröder, J. R. Harris and L. B. Poole, "Structure, Mechanism and Regulation of Peroxiredoxins," Trends in Biochemical Sciences, Vol. 28, No. 1, 2003, pp. 32-40. http://dx.doi.org/10.1016/S0968-0004(02)00003-8

[2] S. Shahrokhian, "Lead Phthalocyanine as a Selective Carrier for Preparation of a Cysteine-Selective Electrode," Analytical Chemistry, Vol. 73, No. 24, 2001, pp. 5972-5978. http://dx.doi.org/10.1021/ac010541m

[3] S. Seshadri, A. Beiser, J. Selhub, P. F. Jacques, I. H. Rosenberg, R. B. D'Agostino, P. W. F. Wilson and P. A. Wolf, "Plasma Homocysteine as a Risk Factor for De- 
mentia and Alzheimer's Disease," The New England Journal of Medicine, Vol. 346, No. 7, 2002, pp. 476-483. http://dx.doi.org/10.1056/NEJMoa011613

[4] X. Chen, T. Pradhan, F. Wang, J. S. Kim and J. Yoon, "Fluorescent Chemosensors Based on Spiroring-Opening of Xanthenes and Related Derivatives," Chemical Reviews, Vol. 112, No. 3, 2012, pp. 1910-1956. http://dx.doi.org/10.1021/cr200201z

[5] H. S. Jung, X. Chen, J. S. Kim and J. Yoon, "Recent Progress in Luminescent and Colorimetric Chemosensors for Detection of Thiols," Chemical Society Reviews, Vol. 42, No. 14, 2013, pp. 6019-6031. http://dx.doi.org/10.1039/c3es60024f

[6] D. Srikun, E. W. Miller, D. W. Domaille and C. J. Chang, "An ICT-Based Approach to Ratiometric Fluorescence Imaging of Hydrogen Peroxide Produced in Living Cells," Journal of the American Chemical Society, Vol. 130, No. 14, 2008, pp. 4596-4597.

http://dx.doi.org/10.1021/ja711480f

[7] K. Kikuchi, H. Takakusa and T. Nagano, "Recent Advances in the Design of Small Molecule-Based FRET Sensors for Cell Biology," TrAC, Trends in Analytical Chemistry, Vol. 23, No. 6, 2004, pp. 407-415. http://dx.doi.org/10.1016/S0165-9936(04)00608-9

[8] C. S. Lim, G. Masanta, H. J. Kim, J. H. Han, H. M. Kim and B. R. Cho, "Ratiometric Detection of Mitochondrial Thiols with a Two-Photon Fluorescent Probe," Journal of the American Chemical Society, Vol. 133, No. 29, 2011, pp. 11132-11135.

http://dx.doi.org/10.1021/ja205081s

[9] G. Kim, K. Lee, H. Kwon and H. Kim, "Ratiometric Fluorescence Imaging of Cellular Glutathione," Organic Letters, Vol. 13, No. 11, 2011, pp. 2799-2801. http://dx.doi.org/10.1021/ol200967w

[10] S. Lim and H. Kim, "Ratiometric Detection of Cysteine by a Ferrocenyl Michael Acceptor," Tetrahedron Letters, Vol. 52, No. 25, 2011, pp. 3189-3190. http://dx.doi.org/10.1016/j.tetlet.2011.03.153

[11] L. Niu, Y. Guan, Y. Chen, L. Wu, C. Tung and Q. Yang, "BODIPY-Based Ratiometric Fluorescent Sensor for Highly Selective Detection of Glutathione Over Cysteine and Homocysteine," Journal of the American Chemical Society, Vol. 134, No. 46, 2012, pp. 18928-18931. http://dx.doi.org/10.1021/ja309079f

[12] P. Das, A. K. Mandal, N. B. Chandar, M. Baidya, H. B. Bhatt, B. Ganguly, S. K. Ghosh and A. Das, "New Chemo- dosimetric Reagents as Ratiometric Probes for Cysteine and Homocysteine and Possible Detection in Living Cells and in Blood Plasma," Chemistry-A European Journal, Vol. 18, No. 48, 2012, pp. 15382-15393. http://dx.doi.org/10.1002/chem.201201621

[13] L. Long, W. Lin, B. Chen, W. Gao and L. Yuan, "Construction of a FRET-Based Ratiometric Fluorescent Thiol Probe," Chemical Communications, Vol. 47, No. 3, 2011, pp. 893-895. http://dx.doi.org/10.1039/c0cc03806g

[14] Z. Guo, S. Nam, S. Park and J. Yoon, "A Highly Selective Ratiometric Near-Infrared Fluorescent Cyanine Sensor for Cysteine with Remarkable Shift and Its Application in Bioimaging," Chemical Science, Vol. 3, No. 9, 2012, pp. 2760-2765. http://dx.doi.org/10.1039/c2sc20540h

[15] H. Li, J. Xu and H. Yan, "Ratiometric Fluorescent Determination of Cysteine Based on Organic Nanoparticles of Naphthalene-Thiourea-Thiadiazole-Linked Molecule," Sensors and Actuators B, Vol. 139, No. 2, 2009, pp. 483-487. http://dx.doi.org/10.1016/j.snb.2009.03.028

[16] X. Zeng, X. Zhang, B. Zhu, H. Jia and Y. Li, “A Highly Selective Wavelength-Ratiometric and Colorimetric Probe for Cysteine," Dyes and Pigments, Vol. 94, No.1, 2012, pp. 10-15. http://dx.doi.org/10.1016/j.dyepig.2011.10.013

[17] O. Rusin, N. N. S. Luce, R. A. Agbaria, J. O. Escobedo, S. Jiang, I. M. Warner, F. B. Dawan, K. Lian and R. M. Strongin, "Visual Detection of Cysteine and Homocysteine," Journal of the American Chemical Society, Vol. 126, No. 2, 2004, pp. 438-439.

http://dx.doi.org/10.1021/ja036297t

[18] T. Kim, D. Lee and H. Kim, "Highly Selective Fluorescent Sensor for Homocysteine and Cysteine," Tetrahedron Letters, Vol. 49, No. 33, 2008, pp. 4879-4881. http://dx.doi.org/10.1016/j.tetlet.2008.06.003

[19] B. Zhu, C. Gao, Y. Zhao, C. Liu, Y. Li, Q. Wei, Z. Ma, B. $\mathrm{Du}$ and $\mathrm{X}$. Zhang, "A4-Hydroxynaphthalimide-derived ratiometric Fluorescent Chemodosimeter for Imaging Palladium in Living Cells," Chemical Communications, Vol. 47, No. 30, 2011, pp. 8656-8658. http://dx.doi.org/10.1039/c1cc13215f

[20] C. R. Yellaturu, M. Bhanoori, I. Neeli and G. N. Rao, "N-Ethylmaleimide Inhibits Platelet-Derived Growth Factor BB-Stimulated Akt Phosphorylation via Activation of Protein Phosphatase 2A," The Journal of Biological Chemistry, Vol. 277, No. 42, 2002, pp. 40148-40155. http://dx.doi.org/10.1074/jbc.M206376200 